\title{
Serum IgE levels in patients with intracranial tumors
}

\author{
George A. Alexiou ${ }^{1}$, Amalia Kallinteri ${ }^{2}$, Eleni Nita², Panagiota Zagorianakou ${ }^{1}$, Stamatina Levidiotou ${ }^{2}$, \\ Spyridon Voulgaris ${ }^{1}$ \\ ${ }^{1}$ Department of Neurosurgery, Medical School, University of Ioannina, 45110 Ioannina, Greece. \\ ${ }^{2}$ Department of Microbiology, Medical School, University of Ioannina, 45110 Ioannina, Greece.
}

\section{A B S T R A C T}

Aim: Several epidemiological studies have shown an inverse correlation between allergy and brain cancer. The purpose of this study was to compare the serum IgE levels between patients with gliomas and nonglial tumors and their possible prognostic role. Methods: A total of 84 patients with intracranial tumors were included in this study. At clinical presentation, estimation of serum IgE levels was assessed by nephelometry. Detailed information regarding the history of allergies was collected by interview. Results: Of the 84 cases, 42 were gliomas, 23 were meningiomas, 16 were metastases and 3 were primary central nervous system lymphomas. Patients with high-grade glioma had lower IgE levels than patients with low-grade glioma. Patients with glioma and meningioma had statistical significant lower serum IgE levels than patients with metastases. Patients with glioblastoma with serum IgE levels greater than $24 \mathrm{U} / \mathrm{mL}$ had a better survival. Conclusion: Patients with glioma and meningioma had lower IgE levels than patients with metastatic lesions. A prognostic role of serum IgE levels was found in glioblastoma. Further studies in larger patient series are required in order to verify our preliminary observations.

Key words: Glioma, IgE, meningioma, metastasis

\section{INTRODUCTION}

Several epidemiological studies have shown an inverse correlation between allergy and brain cancer. ${ }^{[1,2]}$ The exact mechanism of how allergy protects is largely unknown. Plasma IgE levels are a marker of allergy. Patients with gliomas have been reported to have lower IgE levels than controls. ${ }^{[2]}$ Furthermore, meningiomas patients were found to have lower total serum IgE levels than controls, and an inverse correlation was also found between risk of meningioma and history of allergies. ${ }^{[3]}$ To the best of our knowledge, no previous study has examined if significant similarities or differences in serum IgE levels exist among patients with different intracranial tumors. Thus, we aimed to investigate serum IgE levels in patients with different intracranial tumors and a possible prognostic value of serum IgE levels in patients with glioblastoma.

\begin{tabular}{|l|l|}
\hline \multicolumn{2}{|c|}{ Access this article online } \\
\hline Quick Response Code: & \\
\hline & Website: \\
\hline & www.nnjournal.net \\
& DOI: \\
\hline
\end{tabular}

\section{METHODS}

We prospectively studied patients who were operated on for brain tumors in our institute, between April 2010 and February 2014. Patients were included if assessment of IgE levels was performed at first presentation before receiving any treatment. Detailed information regarding the history of allergies was collected by interview using a questionnaire. Questionnaire included the following allergens: foods, dust, animals, plants, stinging or biting insects, cosmetics, drugs, and mold. A history of asthma was also recorded. Personal information, including smoking, alcohol consumption and diet was also included. Serum total IgE levels were measured for all patients by nephelometry (Immage 800, Beckman Coulter). Ethics approval was given by the review board of University of Ioannina.

\section{Statistical analysis}

Mann-Whitney $U$-test was used for two-group comparison. Chi-square and Fisher exact tests were used for categorical independent variables. Survival time was defined as the time between the date at diagnosis and the date of death for deceased patients or to the last follow-up of the surviving patients. The overall survival time was estimated using KaplanMeier methods, and log-rank analysis was performed to compare survival curves between groups. Patients

Correspondence Author: Dr. George A. Alexiou, Department of Neurosurgery, Medical School, University of loannina, 45110 loannina, Greece. E-mail: alexiougrg@yahoo.gr 
who were still alive at last contact were treated as censored events in the analysis. A two-sided $P<0.05$ was considered to be statistically significant.

\section{RESULTS}

Tables 1 and 2 summarize the patient data. Eighty-four patients (44 males, 40 females, mean age $59.3 \pm 13.3$ ) met the inclusion criteria for the study. All patients had a single space-occupying lesion and were operated. The histological diagnosis were 42 gliomas (31 glioblastomas, 4 gliosarcomas, 3 anaplastic astrocytomas, 1 Grade II astrocytoma, 1 pilocytic astrocytoma, 1 oligodendroglioma and 1 oligoastrocytoma), 23 meningiomas (20 benign and 3 atypical meningiomas), 16 metastases (10 lung cancer, 1 ovarian cancer, 2 colon cancer, 1 melanoma and 2 of unknown primary origin) and 3 primary central nervous system lymphomas (PCNSL). Among gliomas, 5 patients reported an allergic condition. In meningiomas, there were 5 patients with an allergic condition and 4 cases in patients with a metastatic lesion. The difference was not statistically significant. No difference in IgE levels was found between men and women $(P=0.7)$. In gliomas the mean IgE levels were $58.9 \pm 87.9 \mathrm{U} / \mathrm{mL}$. Patients with high-grade gliomas had lower IgE levels than patients with low-grade gliomas. However the difference was not statistically significant (median 24 vs. $74.6 \mathrm{U} / \mathrm{mL}, P=0.067)$. In meningiomas, the mean IgE levels were $65.8 \pm 77.7 \mathrm{U} / \mathrm{mL}$. No significant difference was found between benign and atypical meningiomas $(P=0.9)$. In metastatic lesions, the mean IgE levels were $226.8 \pm 203 \mathrm{U} / \mathrm{mL}$. In PCNSL, the mean IgE levels were $150.8 \pm 240.9 \mathrm{U} / \mathrm{mL}$. Patients with gliomas had statistical significant lower IgE levels than patients with metastases (median 32.7 vs. $199 \mathrm{U} / \mathrm{mL}$, $P=0.0022)$. Patients with meningiomas had statistical significant lower IgE levels than metastases (median

\begin{tabular}{lc}
\hline Table I: Patients data & \\
\hline Patient characteristics & $\mathbf{n}(\%)$ \\
\hline Gender & \\
$\quad$ Male & $44(52.3)$ \\
Female & $40(47.7)$ \\
Age & \\
$>65$ & $51(60.7)$ \\
$<65$ & $33(39.3)$ \\
Reported allergy asthma & $14(16.7)$ \\
Yes & $70(83.3)$ \\
No & \\
\hline
\end{tabular}

\begin{tabular}{lc}
\hline Table 2: IgE levels according to diagnosis \\
\hline Histology & \\
\hline IgE levels (U/mL) \\
\hline Hioma & \\
Low-grade & $42.7 \pm 47.6$ \\
Meningioma & $117.8 \pm 119$ \\
Benign & \\
Atypical & $68.2 \pm 81.6$ \\
Metastases & $54.3 \pm 33.3$ \\
\hline
\end{tabular}

37.6 vs. $199 \mathrm{U} / \mathrm{mL}, P=0.01)$. There was no significant difference between gliomas and meningiomas with respect to IgE levels $(P=0.8)$.

\section{Survival analysis in glioblastoma}

Two patients died in the immediate postoperative period whereas another two patients were lost to follow-up. After a mean follow-up period of 12.4 months, 10 patients were alive. Using receiver operator characteristic curve analysis a cut-off IgE value of $24 \mathrm{U} / \mathrm{mL}$ was identified as the best predicting survival with $72.2 \%$ sensitivity and $100 \%$ specificity. Patients with IgE value exceeding $24 \mathrm{U} / \mathrm{mL}$ lived longer $(P=0.01)$.

\section{DISCUSSION}

The present study investigated serum IgE levels in patients with intracranial tumors. The results showed that glioma and meningioma patients had lower serum IgE levels than patients with a metastatic brain lesion. Patients with high-grade gliomas had lower serum IgE levels than patients with low-grade gliomas. In glioblastomas, patients with serum IgE levels exceeding $24 \mathrm{U} / \mathrm{mL}$ had a better survival.

A large body of research showed that allergies may play a role in a diverse group of cancers including brain tumors, leukemia, pancreatic cancer, and other tumors. ${ }^{[4]}$ An inverse association has been reported between allergy history and cancer risk. ${ }^{[4]}$ Turner et al. studied 793 glioma, 832 meningioma, 394 acoustic neuroma, 84 parotid gland tumor cases and 2,520 controls and found a significant inverse association between a history of any allergy and glioma, meningioma and acoustic neuroma. ${ }^{[5]}$ Various hypotheses have been proposed to explain the associations between allergy and cancer. Single-nucleotide polymorphisms of inflammatory-related genes, such as interleukin-4, FCER1A and interleukin-10, have been associated with glioma risk. ${ }^{[6]}$ In gliomas, a large nested case-control study showed that a positive test for increased concentrations of total $\operatorname{IgE}$ (> $100 \mathrm{kU} / \mathrm{L}$ ) was statistically significantly associated with decreased risk of glioma compared with a negative test. A lower risk for glioblastoma and glioma at least 20 years before diagnosis was found for those that tested positive for total IgE. ${ }^{[7]}$ Wiemels et al. found that IgE levels were strongly inversely associated with glioma and in particular, IgE to dietary allergens. A weaker association was found for respiratory allergens. ${ }^{[2]}$ Antihistamine use was strongly associated with glioma risk when allergy or asthma history existed, but not among those with a negative history ${ }^{[8]}$ In the present study, we found that glioma patients had the lowest IgE levels. High-grade tumors had lower serum IgE levels than low-grade tumors. IgE levels should be measured at presentation since dexamethasone, which is, usually, administered 
in brain tumor patients, increases IgE levels. ${ }^{[9]}$ Lin et al. also studied the IgE levels in glioma patients and reported that an increase in IgE levels posttreatment correlated with better survival. ${ }^{[10]}$ In the present study, we found a prognostic significance of pretreatment IgE levels in glioblastoma patients. This has not been previously reported and required further investigation.

Meningiomas are the most common benign intracranial tumor and account for nearly 30\% of all intracranial tumors. ${ }^{[11]}$ Meningiomas have also been showed to have an inverse relationship with history of allergies and meningioma patients had lower total serum IgE than controls. ${ }^{[3]}$ A meta-analysis investigating the association of meningioma with the overall and specific allergic conditions found only eczema to have a significant inverse association. No significant association was found for asthma and hay fever. ${ }^{[12]}$ In their study, Schlehofer et al. they found that the risk of glioma was inversely correlated to allergic sensitization; however, this was not significant for meningiomas. ${ }^{[13]}$ In the present study, no significant difference in serum IgE levels was found between glioma and meningioma.

Regarding other cancers, several studies have consistently found that self-reported allergies are associated with lower risk of pancreatic cancer. ${ }^{[14]}$ Bosetti et al. reported an inverse correlation with history of allergy for cancer of the oral cavity, pharynx, esophagus, colon, rectum and larynx. ${ }^{[15]}$ Nevertheless, a recent study showed an increased risk of hematologic malignancies in women with a history of allergies to airborne allergens. ${ }^{[16]}$ In the present study, 2 metastatic lesions from patients with colon cancer were found. Patients with metastatic disease had significant higher IgE levels than patients with gliomas and meningiomas. This finding needs to be verified on a larger scale.

The present study has several limitations. First, the results are based on a series of 84 patients and should, therefore, be considered preliminary. Second, given that only 31 patients had glioblastoma, the reported prognostic significance of IgE levels should be dealt with caution and needs further investigation in larger studies. Another important limitation pertains to the absence of a control group. Several previous studies consistently reported lower IgE levels for brain tumor patients than controls. Thus we focused on the possible impact of tumor type on serum IgE levels.

In conclusion, the present study shows that patients with glioma and meningioma have lower IgE levels than patients with metastatic lesions. Patients with high-grade gliomas have lower serum IgE levels than patients with low-grade gliomas. In the glioblastoma, serum IgE levels are associated with tumor aggressiveness. Since serum
IgE levels can be easily measured, further research is required to validate our preliminary observations.

\section{REFERENCES}

1. Linos E, Raine T, Alonso A, Michaud D. Atopy and risk of brain tumors: a meta-analysis. J Natl Cancer Inst 2007;99:1544-50.

2. Wiemels JL, Wiencke JK, Patoka J, Moghadassi M, Chew T, McMillan A, Miike R, Barger G, Wrensch M. Reduced immunoglobulin $\mathrm{E}$ and allergy among adults with glioma compared with controls. Cancer Res 2004;64:8468-73.

3. Wiemels JL, Wrensch M, Sison JD, Zhou M, Bondy M, Calvocoressi L, Black PM, Yu H, Schildkraut JM, Claus EB. Reduced allergy and immunoglobulin $\mathrm{E}$ among adults with intracranial meningioma compared to controls. Int J Cancer 2011;129:1932-9.

4. Turner MC. Epidemiology: allergy history, IgE, and cancer. Cancer Immunol Immunother 2012;61:1493-510.

5. Turner MC, Krewski D, Armstrong BK, Chetrit A, Giles GG, Hours M, McBride ML, Parent ME, Sadetzki S, Siemiatycki J, Woodward A, Cardis E. Allergy and brain tumors in the interphone study: pooled results from Australia, Canada, France, Israel, and New Zealand. Cancer Causes Control 2013;24:949-60.

6. Backes DM, Siddiq A, Cox DG, Calboli FC, Gaziano JM, Ma J, Stampfer M, Hunter DJ, Camargo CA, Michaud DS. Single-nucleotide polymorphisms of allergy-related genes and risk of adult glioma. J Neurooncol 2013;113:229-38.

7. Schwartzbaum J, Ding B, Johannesen TB, Osnes LT, Karavodin L, Ahlbom A, Feychting M, Grimsrud TK. Association between prediagnostic IgE levels and risk of glioma. $J$ Natl Cancer Inst 2012;104:1251-9.

8. Amirian ES, Marquez-Do D, Bondy ML, Scheurer ME. Antihistamine use and immunoglobulin $\mathrm{E}$ levels in glioma risk and prognosis. Cancer Epidemiol 2013;37:908-12.

9. Barnes PJ. Corticosteroids, IgE, and atopy. J Clin Invest 2001;107:265-6.

10. Lin Y, Jin Q, Zhang GZ, Wang YJ, Jiang T, Wu AH, Wang JF, Qiu XG. Increase of plasma IgE during treatment correlates with better outcome of patients with glioblastoma. Chin Med J (Engl) 2011;124:3042-8.

11. Alexiou GA, Gogou P, Markoula S, Kyritsis AP. Management of meningiomas. Clin Neurol Neurosurg 2010;112:177-82.

12. Wang M, Chen C, Qu J, Xu T, Lu Y, Chen J, Wu S. Inverse association between eczema and meningioma: a meta-analysis. Cancer Causes Control 2011;22:1355-63.

13. Schlehofer B, Siegmund B, Linseisen J, Schüz J, Rohrmann S, Becker S, Michaud D, Melin B, Bas Bueno-de-Mesquita H, Peeters PH, Vineis P, Tjonneland A, Olsen A, Overvad K, Romieu I, Boeing H, Aleksandrova K, Trichopoulou A, Bamia C, Lagiou P, Sacerdote C, Palli D, Panico S, Sieri S, Tumino R, Sanchez MJ, Rodriguez L, Dorronsoro M, Duell EJ, Chirlaque MD, Barricarte A, Borgquist S, Manjer J, Gallo V, Allen NE, Key TJ, Riboli E, Kaaks R, Wahrendorf J. Primary brain tumours and specific serum immunoglobulin E: a case-control study nested in the European Prospective Investigation into Cancer and Nutrition cohort. Allergy 2011;66:1434-41.

14. Cotterchio M, Lowcock E, Hudson TJ, Greenwood C, Gallinger S. Association between allergies and risk of pancreatic cancer. Cancer Epidemiol Biomarkers Prev 2014;23:469-80.

15. Bosetti C, Talamini R, Franceschi S, Negri E, Giacosa A, La Vecchia C. Allergy and the risk of selected digestive and laryngeal neoplasms. Eur J Cancer Prev 2004;13:173-6.

16. Shadman M, White E, De Roos AJ, Walter RB. Associations between allergies and risk of hematologic malignancies: results from the VITamins and lifestyle cohort study. Am J Hematol 2013;88:1050-4.

Cite this article as: Alexiou GA, Kallinteri A, Nita E, Zagorianakou P, Levidiotou S, Voulgaris S. Serum IgE levels in patients with intracranial tumors. Neuroimmunol Neuroinflammation 2015;2(1):15-7.

Source of Support: Nil. Conflict of Interest: No.

Received: 19-08-2014; Accepted: 30-09-2014 